\title{
NOTE ON THE FORMATION PROCESS OF THRUST STRUCTURES IN YOUNG SEA ICE
}

\author{
By Moira Dunbar
}

(Directorate of Physical Research (Geophysics), Defence Research Board, Ottawa)

THE interlocking thrusts commonly found in very young sea ice have been described and discussed in the Journal of Glaciology by Weeks and Anderson (1958) and Dunbar (1960).

One of the chief problems in the study of these structures is that as they form only in very thin ice it is very difficult to observe the formation process. It is, however, possible to observe it from a ship, and this I was able to do in the summer of $196 \mathrm{I}$ from the icebreaker C.M.S. John A. Macdonald in the Canadian Arctic.

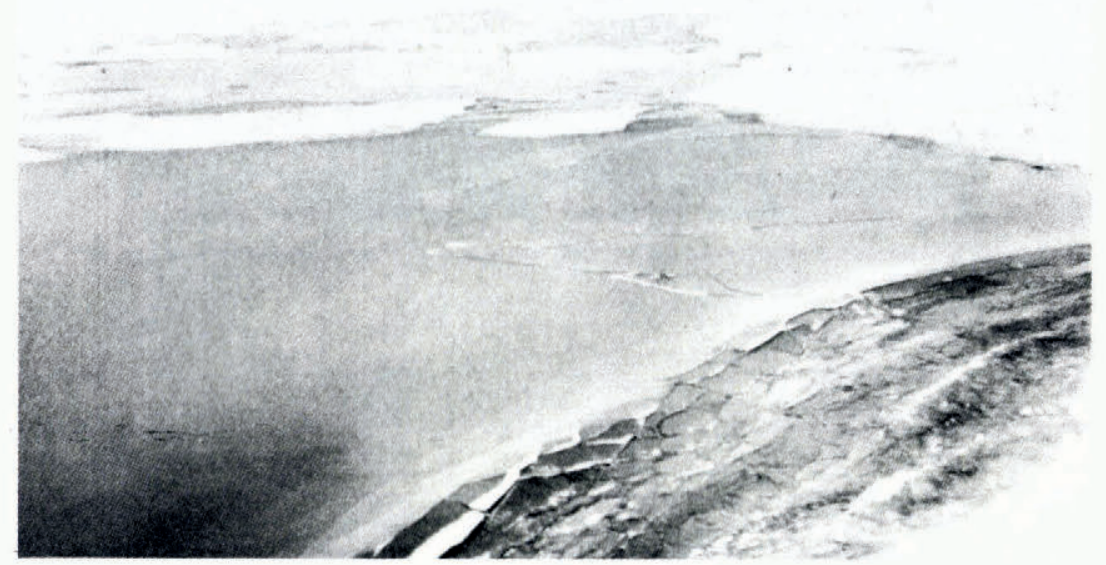

Fig. 1. Brittle ice crust on a surface puddle breaking on the bow wave of a ship. Note the small pieces and tendency towards straight lines and right angles

As a vessel ploughs through young ice the ice reacts in various ways according to its type and thickness. If it is sufficiently lacking in cohesion the ship makes no apparent impression on the ice alongside, leaving it undisturbed. If the ice is hard and brittle it breaks with a little tinkling sound, usually in rectangular pieces (Fig. I). This is most common in the ice crust that forms on fresh-water surface puddles, but it is also encountered in open water, either where there is a surface layer of very low salinity, or where the ice is thicker and has lost some of its elasticity. Where the ice is sufficiently cohesive to form a crust, but still has enough elasticity to bend with the ripples of the bow wave, thrusts are formed, and it is possible to watch them forming by the hour when conditions are suitable (Fig. 2).

The process seems to me to be as follows. A series of small folds is formed in the ice by the divergent crests of the bow wave. The friction caused by the ice tends to slow down the movement of the crests, and to set up a process of tightening or twisting of the folds which causes the ice to rupture. This rupture occurs not along the line of any one fold or wave crest but along the line formed by the combination of the crests (Fig. 3). Thus although in 
general the line of break is straight, in detail the outline is uneven. The rupture occurs suddenly with a little upward burst, and the ice falls back with an uneven interlocking overlap. Although this part of the process is so quick that it is hard to see exactly what does happen, this pattern

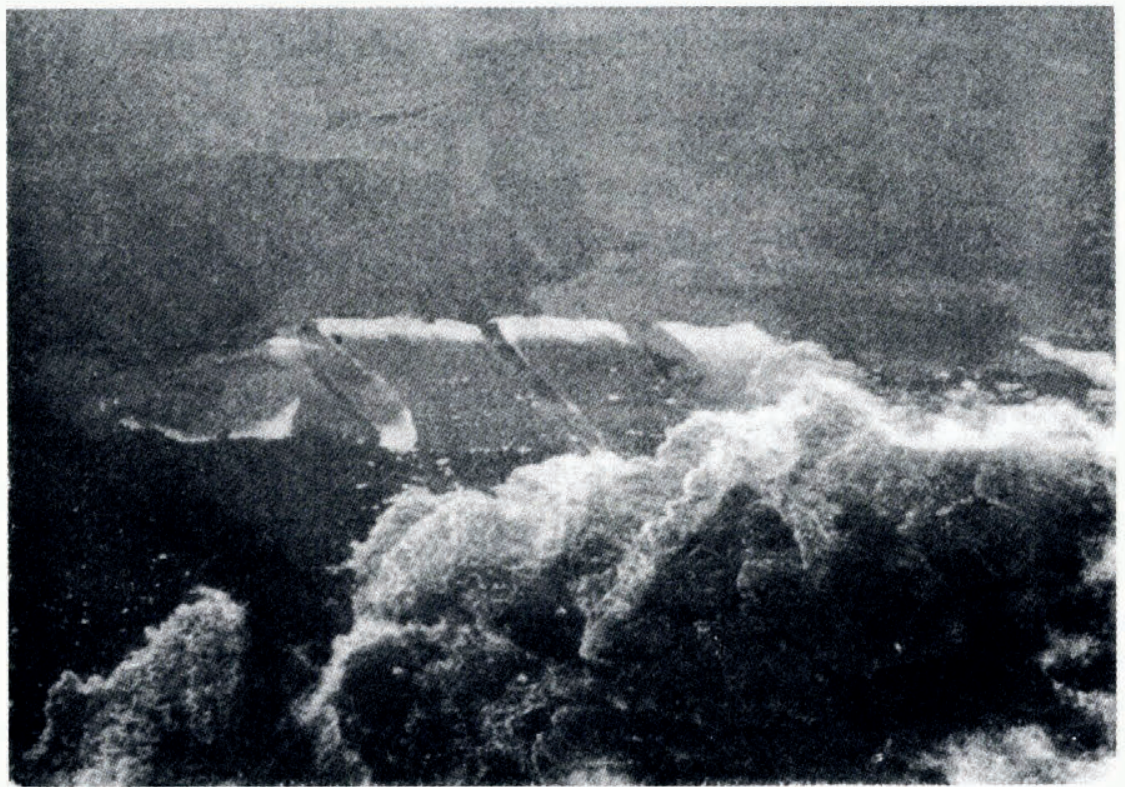

Fig. 2. Typical interlocking thrusts formed by the ship's passage and about to be destroyed by the same agency

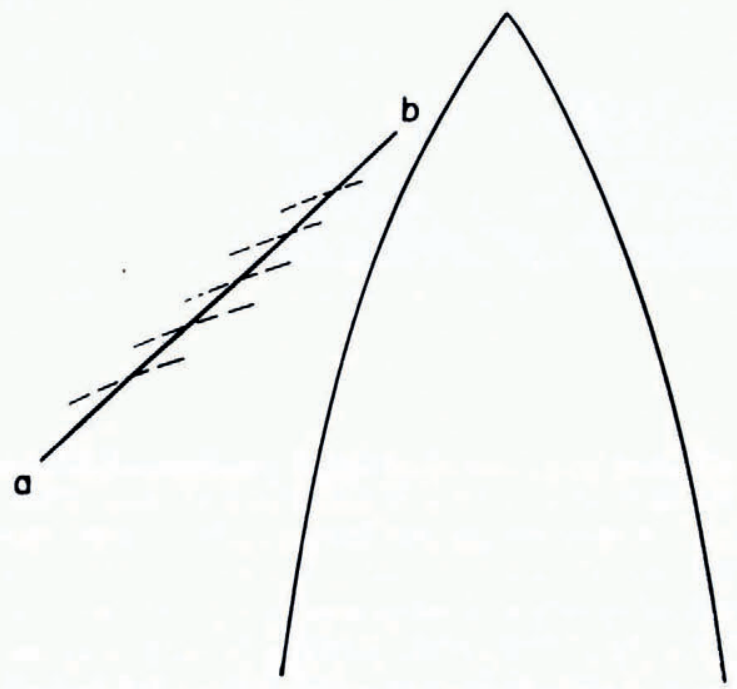

Fig. 3. Rough sketch showing the approximate relationship between the line of fracture $(a-b)$ and the crests of the bow wave (dashed lines)

seems almost inevitable, and indeed it would be rather surprising if one sheet were to end up underneath the other right along the break.

From here on it is merely a matter of lateral pressure and the thinness and elasticity of the ice, which tears extremely readily but does not break easily. Thrusts formed by a ship are 
always short and are usually destroyed before the ship has passed. Very often they become S-shaped, owing to the change in the direction of thrust as the ship's shoulder passes them (Fig. 4).

In nearly all the cases I observed, the break occurred in this way at the time of the thrusting. Where a break already existed it was more common for simple rafting to result.

It seems reasonable to assume that in nature the formation process is similar. A very small unevenness of the break-line would appear to be sufficient to result in interlocking, provided that the pressure that causes the thrusting also causes the break. When two sheets of ice already separated come together, interlocking may or may not result, depending on such factors as unevenness of outline, as suggested by Weeks and Anderson (1958) and obliquity of wave

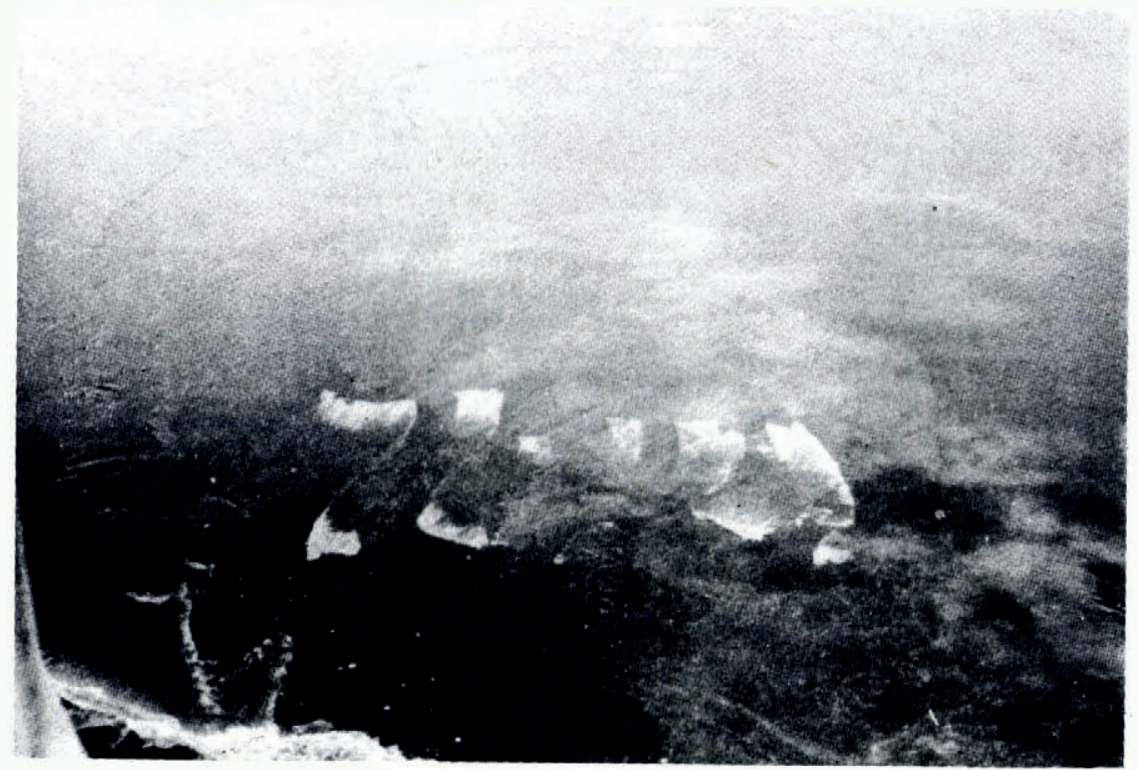

Fig. 4. S-shaped thrusts resulting from the change of direction of thrust with the passing of the ship's shoulder. Taken from the bridge over the starboard side. On the extreme left may be seen an indication of the capacity of the ice to form folds

angle (Dunbar, 1960). Thus the chances for interlocking thrusts to form are high, and this is borne out by the observed fact that they are much more common than simple rafting.

In this connection it seems to me that in many respects this type of overthrusting in very young ice is comparable to ridging in thicker ice. When two thicker ice floes meet they either overlap completely and raft, or they butt into each other and form a ridge. In the same way very thin ice either rafts or forms interlocking thrusts. If the ice had greater strength and lacked the capacity to tear, the result of an interlocking overlap would be a ridge rather than a thrust. And just as ridges are more common than rafting in thicker ice, so interlocking thrusts are commoner than simple rafting in thin ice.

The speed with which these structures can form is amazing. On 7 September $196 \mathrm{I}$ the John A. Macdonald anchored in McDougall Sound, off the south-east coast of Bathurst Island, in open water. It was an almost dead calm day and as soon as the sun dropped below the horizon a skin of ice began to form over the water. By next morning, still in almost calm conditions, interlocking thrusts had formed all around, apparently as a result of tidal currents acting against the coasts. The ice crust at this time was moving south past the ship at a rate of about one-third knot (60o m./hr.), leaving an open "wake" behind the ship, which was still at anchor. 
In this instance the thickness of the ice was estimated to be about $\mathrm{I}-2 \mathrm{~cm}$. Unfortunately it was not possible on any occasion to measure the ice thickness, but it is doubtful that we ever observed thrusting in ice of more than 5 or $6 \mathrm{~cm}$. The longest thrusts seen were in the order of 10 to $20 \mathrm{~m}$.

I am indebted to Lieut. Charles M. Keeler, U.S.N., for an account and photograph of this same formation process observed from U.S.S. Edisto in the Antarctic. He states that he has seen the thrusts in ice from $\mathrm{I}$ to $\mathrm{I} 0 \mathrm{~cm}$. thick, but does not mention whether these thicknesses were measured or estimated. He has also observed thrusts forming in ice of different thicknesses, and in such cases the thicker ice remained unbroken, only the thinner sheet tearing and thrusting over and under the thicker. This is the situation illustrated in Weeks and Anderson's diagram.

$M S$. received 26 January 1962

\section{R E F E R E N C E S}

Dunbar, M. 1960. Thrust structures in young sea ice. Journal of Glaciology, Vol. 3, No. 28, p. 724-32.

Weeks, W. F., and Anderson, D. L. 1958. Sea ice thrust structures. Journal of Glaciology, Vol. 3, No. 23, p. $173-75$. 